\title{
The Bulletin of Environmental Contamination and Toxicology: The Next Chapter
}

\author{
Erin R. Bennett ${ }^{1}$
}

Received: 9 March 2016/Accepted: 9 March 2016/Published online: 16 March 2016

(c) Springer Science+Business Media New York 2016

Six years ago, I was approached by Springer to take over as the fourth Editor-in-Chief (EiC) of the Bulletin of Environmental Contamination and Toxicology (BECT). With little hesitation, I agreed that this would be a challenging but exciting new step in my scientific career. In addition, I was honored to become part of a Journal that had such a long storied history. I remember utilizing the Journal in the late $80 \mathrm{~s}$ as a "go to" journal, as it contained original environmental research papers dealing with the environmental fate and effects of pesticides and PCBs. In addition, the journal was always easily found in the library stacks due to its unique orange cover.

My journey as an EiC began in 2012. This was a transitional year where I had the opportunity to work directly with the outgoing EiC, Dr. Herbert Nigg. This was an amazing chance for me to really learn and understand the ins and outs of being an EiC. It also gave me a glimpse into all the hard work that Dr. Nigg, and the BECT editorial board, had put into the journal during his 30 -year tenure. I am very thankful for his patience and sound advice that allowed me to get up and running on my own following this transitional year.

The first step in taking over the journal was to form a new Editorial Board. My goal was to strike a balance between the existing board and new incoming board members. I was very pleased that many of the existing Editors/Editorial Board members agreed to stay on board. This further helped with the transition into the next phase of BECT. Today, the Editorial Board is made up of 15

Erin R. Bennett

ebennett@uwindsor.ca

1 Great Lakes Institute for Environmental Research, University of Windsor, Windsor, ON, Canada
Senior Editors and over 130 Editorial Board Editors representing 22 countries (a list can be found on inside cover of BECT), each having his/her own unique area of expertise. I would like to thank them for all of their hard work in helping me during the transition and for their continued support.

The second step was to refocus the Aims and Scope of the journal. The main rationale for updating the Aims and Scope was that the new Board found that the current version was too broad and that BECT needed to be focused back to papers that dealt more specifically with environmental contamination and toxicology. Another reason for this was a significant increase in the annual submission rate. Since 2009, the submission rate had more than doubled. This was partly due to increased submissions from Asia and the Middle East (Drouillard and Bennett 2015). With this growing submission rate and advice from Dr. Nigg and BECT's Senior Editors, the Aims and Scope were refocused. For example, food safety and basic monitoring studies were no longer considered.

One of the biggest challenges that I faced when I took over as EiC was to encourage many of my colleagues and fellow researchers to consider publishing in BECT. Many of them had published in BECT in the past but had not considered BECT in recent years since there were so many other journal options that had developed in this field of research. Interestingly, BECT was one of the only options in the 60, 70 and early 80 s. To aid in the resurgence of this journal, I spent a great deal of time reintroducing the Journal and explaining the essential role that a bulletin style journal plays in scientific research. Basically, it seemed that many of my colleagues and fellow researchers were fixated on Impact Factor and had not really taken the time to consider the importance of this journal as an outlet for certain types of research and datasets. All in all, BECT 
is a perfect outlet for the smaller, maybe less flashy, datasets or studies that provide proof of concept or illustrate a small piece of a bigger research question. Not to mention that BECT is one of the oldest environmental based journals.

As part of our efforts to encourage publishing in BECT, we have added new publishing options for authors. There is now an option to publish "Focused Reviews" in BECT. These reviews follow a similar page limit restriction as the "Original Research" option, but give an author a chance to really key in on a specific area of their research without the constraints of the standard extended review. In addition, we have opened an option called "Retrospectives" to provide authors an opportunity to discuss their research area in light of their earlier work that was published in BECT. This content, no more than 2 pages, will be open for free access to readers. This concept was initiated as a way to celebrate the 50th Anniversary of BECT and we feel that it presents a useful platform for future discussions regarding past BECT publications.

Finally, I was very excited about the upcoming 50th Anniversary of BECT when I took over as EiC. With support from BECT's Editorial Board, we have been working hard on preparing special content for 2016 to celebrate this incredible achievement. In addition, I am pleased to have two of BECT's Senior Editors, Daniel Call and Joseph Gorsuch, helping with the organization and editing of submissions related to the anniversary, including an introduction to the special year (Call and Gorsuch 2016).

As part of the 50th Anniversary of BECT, we invited two past EiC's to submit editorials that highlighted their time with the journal. We are very grateful that both Dr. John Hylin (BECT Founding Editor) and Dr. Nigg responded to this invitation. Dr. Hylin submitted a retrospective of the earliest days of BECT (Hylin 2016: February 2016 issue of BECT) while Dr. Nigg (the third $\mathrm{EiC}$ of BECT) submitted a historic summary of his tenure as EiC (Nigg 2016; March 2016 issue of BECT). Please take the time to look back at these two editorials that are freely accessible to all, as they provide an interesting picture of the early days of the journal and its journey through time. It should be noted that the second EiC was Dr. Yutaka Iwata (1978-1983). Dr. Iwata was a Post-Doc at UC Riverside working with the EiC of Residue Reviews (now known as Reviews of Environmental Contamination and Toxicology), Dr. Francis Gunther, during his term as the EiC of BECT (Nigg 2016). Sadly, I was not able to reach Dr. Iwata for his input.

We have also reached out to some of the authors of topcited papers in BECT (many are from the early 70s) to submit retrospectives on the role BECT played in affecting and molding current research in their respective fields. We look forward to seeing these submissions in upcoming issues of BECT.

On behalf of myself and BECT's Editorial Board, I would like to thank the Springer staff for all of their hard work and to congratulate all of the past editors and authors for their contributions over these past 50 years. I am confident that BECT will have continued success for years to come. I also would like to extend an invitation to you to consider the submission of an article in 2016 to help in the celebration of this important milestone.

\section{References}

Call DJ, Gorsuch JW (2016) Celebrating 50 years of publication! Bull Environ Contam Toxicol 96:1-2

Drouillard JG, Bennett ER (2015) The changing face of BECT: a citation analysis covering 1966-2009. Bull Environ Contam Toxicol 94:1-5

Hylin J (2016) Origin of the bulletin of environmental contamination and toxicology. Bull Environ Contam Toxicol 96:137-138

Nigg HN (2016) A most interesting and wonderful time as an editor. Bull Environ Contam Toxicol 96:271-272 